\title{
Studies on the Performance of Self Healing of Plastic Cracks Using Natural Fibers in Concrete
}

\author{
Velu Saraswathy ${ }^{1} \cdot$ Seung-Jun Kwon ${ }^{2 *} \cdot$ Subbiah Karthick ${ }^{1}$ \\ (Received June 13, 2014 / Revised June 20, 2014 / Accepted June 24, 2014)
}

Addition of fibers in cement or cement concrete may be of current interest, but this is not a new idea or concept. Fibers of any material and shape play an important role in improving the strength and deformation characteristics of the cement matrix in which they are incorporated. The new concept and technology reveal that the engineering advantages of adding fibers in concrete may improve the fracture toughness, fatigue resistance, impact resistance, flexural strength, compressive strength, thermal crack resistance, rebound loss, and so on. The magnitude of the improvement depends upon both the amount and the type of fibers used. In this paper, locally available waste fibers such as coir fibers, sisal fibers and polypropylene fibers have incorporated in concrete with varying percentages and $\mathrm{I} / \mathrm{d}$ ratio and their effect on compressive, split, flexural, bond and impact resistance have been reported.

Keywords : Coir fiber, Sisal fiber, Polyethylene fiber, Bond strength, Modulus of rupture, Crack pattern, Deflection, Impact resistance

\section{INTRODUCTION}

It is widely accepted within the concrete industry that traditional concrete mixes are prone to plastic shrinkage during the setting phase and this can often lead to cracking. The addition of relatively small amounts of fiber reinforcement can effectively eliminate this problem by controlling this early-age plastic shrinkage cracking. Not only fiber concrete is easy and cost effective to use, but it also enables to produce a hardened concrete which has Improved surface quality, greater impact resistance, and increased damage resistance. When the loads imposed on concrete approach that for failure cracks will propagate sometimes rapidly, fibers in concrete provide a means of arresting the cracks growth (Sounthararajan et al., 2013). Fibers can improve the toughness, the flexural strength or both, and are chosen on the basis of their availability, cost and fiber properties. Polypropylene fibers significantly increase concrete toughness but have little effect on tensile strength (Vinu and Pandya, 2010; Sounthararajan and Sivakumar, 2013; Singh et al., 2010).

Plastic shrinkage cracking of concrete occurs when it is exposed to drying environment while it is still in plastic form. Normally it occurs within the first few hours after the concrete is placed and before it attains any significant strength. The adverse effects of drying shrinkage at a very initial phase include an unsightly and non/uniform appearance on the concrete surface. Later, the plastic shrinkage cracks become critical weak points for aggressive substances to penetrate into the internal portion of concrete leading to the acceleration of other detrimental forms of concrete deterioration. Consequently, the performance, serviceability, durability, and aesthetic qualities of concrete structures are reduced. Controlling plastic shrinkage cracking in concrete is essential for developing more durable and longer lasting structures at a minimum life cycle cost (Hwang et al., 2003; Ramujee, 2013).

Fiber reinforced concrete is a new class of strong, tough and highly durable material (Banthia and Gupta, 2006; Sivakumar and Santhanam, 2007; Nanni et al., 1993; Li et al., 2004; Ozger

\footnotetext{
* Corresponding author E-mail: jjuni98@hannam.ac.kr

${ }^{1}$ Corrosion Protection Division, Central Electrochemical Research Institute, India

${ }^{2}$ Hannam University, Civil and Environmental Eng., Daejeon, 306-791, Korea
} 
et al., 2013). Fiber in the cement based matrix acts as a crack arrester which restricts the growth of flow in the matrix, preventing these from widening under load in to cracks which cause failure (Atis et al., 2013; Song et al., 2005; Sekar, 2004; Hwang et al., 2003; Karahan and Atis, 2011; Ramadoss and Nagamani, 2008). The inclusion of randomly oriented, discrete fibers in concrete, mortar, and cement paste can enhance many of the engineering properties of the base such as fracture toughness, flexural strength and resistance to fatigue, impact, thermal shock or sapling (Mtasher et al., 2011; Shukla, 2011; Nataraja et al., 2005; Nili and Afroughsabet, 2010). Fiber reinforcement is likely to be used if these properties can be exploited in conjunction with advantages in construction and fabrication techniques (Kannan et al., 2010; Kayail, 2004; Zhang and Li, 2013).

In the present investigation, a modified fiber reinforced concrete has been made using the waste product rice husk ash in different percentages along with natural fibers such as coconut and polypropylene fibers in different percentages. The physical and chemical properties of the modified fiber reinforced concrete have been studied systematically. Mechanical properties such as compressive, flexural, splitting tensile, impact and bond strength are also studied. From the results it has been observed that compressive strength, flexural and split tensile strength are found to increase with fiber additions and the impact and toughness resistance are also found to increase. Another important observation is that the addition of fiber has not affected the bond strength of the modified concrete. The ductility of the concrete is improved very much by the addition of fibers.

\section{Experimental Details}

\subsection{Material used}

\subsubsection{Cement, aggregates, and steel used}

Ordinary Portland Cement (OPC) of 43Grade conforming to (IS: 8119-1989) was used for the investigation. Local clean river sand passing through $2.36 \mathrm{~mm}$ sieve (fineness modulus of medium sand equal to 2.6). Conforming to grinding zone
3 of IS:383-1970. Graded aggregates of normal size greater than $4.75 \mathrm{~mm}$ and less than $16 \mathrm{~mm}$ was used. For mixing water, portable water with $\mathrm{pH} 7$ to $8.5\left(\mathrm{Cl}^{-}=40 \mathrm{ppm}\right.$, Hardness=240ppm) was used. Thermo mechanically Treated (TMT) rebar of size $12 \mathrm{~mm}$ dia, and $70 \mathrm{~mm}$ length was used.

\subsubsection{Fibers and rice husk used}

Coconut fibers are added to the concrete in terms of volume fraction of $0.125 \%, 0.25 \%$ and $0.375 \%$. Coconut fibers of length $20 \mathrm{~mm}$ and $40 \mathrm{~mm}$ were used in concrete. Polypropylene fibers are added to the concrete in terms of volume fraction of $0.125 \%, 0.25 \%$ and $0.375 \%$. Polypropylene fibers of length $20 \mathrm{~mm}$ and $40 \mathrm{~mm}$ were used in concrete.

Rice husk ash is produced by burning rice husk which contains large proportion of silica. To achieve amorphous state, rice husk was burnt at a controlled temperature.

\subsection{Preliminary test}

Fibers are kept in water for $24 \mathrm{hrs}$. After $24 \mathrm{hrs}$. $\mathrm{pH}$ of the water was measured. If $\mathrm{pH}$ value is less than 7 then fibers are subjected to alkali treatment in $1 \% \mathrm{NaOH}$ solution. If there is any colour change occurs then the fibers are not suitable for use in concrete.

\subsection{Tests carried out}

The Test comprised of cube compression test, cylinder splitting tensile test, flexural strength test, Impact resistant test and pull out/bond test.

\subsection{Concrete Preparation}

Concrete specimens were cast using 1: 1.86: 3.696 mix w/c ratio of 0.52 . Fibers and $\mathrm{RHA}$ (Rice Husk Ash) were added in various proportions as shown in Table 1 and 2. The proportions of fibers and RHA are weighed and placed in various containers along with required amount of sand. Then coarse aggregate is mixed thoroughly. Water is added in required quantity. The moulds were cleaned and oil was applied. The concrete prepared above was placed in three layers in the 
Table 1. Mix proportions of coconut fiber with rice husk ash used for the study

\begin{tabular}{c|c|c|c|c}
\hline $\begin{array}{c}\text { Mix } \\
\text { designation }\end{array}$ & OPC(\%) & RHA(\%) & $\begin{array}{c}\text { Coconut fiber } \\
\mathrm{V}_{\mathrm{f}}(\%)\end{array}$ & w/c ratio \\
\hline 1 & 100 & - & - & 0.52 \\
\hline 2 & 90 & 10 & - & 0.52 \\
\hline 3 & 80 & 20 & - & 0.52 \\
\hline 4 & 100 & - & 0.125 & 0.52 \\
\hline 5 & 90 & 10 & 0.125 & 0.52 \\
\hline 6 & 80 & 20 & 0.125 & 0.52 \\
\hline 7 & 100 & - & 0.250 & 0.52 \\
\hline 8 & 90 & 10 & 0.250 & 0.52 \\
\hline 9 & 80 & 20 & 0.250 & 0.52 \\
\hline 10 & 100 & - & 0.375 & 0.52 \\
\hline 11 & 90 & 10 & 0.375 & 0.52 \\
\hline 12 & 80 & 20 & 0.375 & 0.52 \\
\hline
\end{tabular}

Table 2. Mix proportions of poly propylene fiber with rice husk ash used for the study

\begin{tabular}{c|c|c|c|c}
\hline $\begin{array}{c}\text { Mix } \\
\text { designation }\end{array}$ & OPC(\%) & RHA(\%) & $\begin{array}{c}\text { Coconut fiber } \\
\mathrm{V}_{\mathrm{f}}(\%)\end{array}$ & w/c ratio \\
\hline 13 & 100 & - & 0.125 & 0.52 \\
\hline 14 & 90 & 10 & 0.125 & 0.52 \\
\hline 15 & 80 & 20 & 0.125 & 0.52 \\
\hline 16 & 100 & - & 0.25 & 0.52 \\
\hline 17 & 90 & 10 & 0.25 & 0.52 \\
\hline 18 & 80 & 20 & 0.25 & 0.52 \\
\hline 19 & 100 & - & 0.375 & 0.52 \\
\hline 20 & 90 & 10 & 0.375 & 0.52 \\
\hline 21 & 80 & 20 & 0.375 & 0.52 \\
\hline
\end{tabular}

mould. For each layer, compaction was done using table vibrator to fill the voids. At last, finishing is done and excess concrete is removed. After 24 hours the specimens were removed, from the mould and subjected to water curing for 28 days.

\subsection{Test Procedure}

\subsubsection{Cube Compressive Strength Test (ASTM C109/ C109M)}

The compressive strength is one of the most important properties of concrete. Concrete specimens of $100 \times 100$ $\times 100 \mathrm{~mm}$ cubes were cast with different types of fibers such as coconut coir, polypropylene fibers in various percentages such as $0.125,0.25$ and $0.375 \%$ along with 10 and $20 \%$ replacement levels of RHA. After 24 hrs the specimens were demolded and subjected to cure for 28 days in ordinary tap water. After 28 days of curing, the cubes are then allowed to become dry for some hours. For each system triplicate specimens were cast. The cubes are tested in the compression-testing machine (60T capacity). The load was applied at the rate of $140 \mathrm{kN} / \mathrm{min}$. The ultimate load at which the cube fails was taken. Compressive strength was calculated using the following formula.

$$
f_{c u}=\frac{\text { Load at failure }}{\text { Cross sectional area }}\left(\mathrm{N} / \mathrm{mm}^{2}\right)
$$

\subsubsection{Split Tensile Test: (ASTMC 496-90)}

Split tensile test was carried out as per ASTM C496-90. Concrete cylinders of size $60 \mathrm{~mm}$ diameters and $100 \mathrm{~mm}$ height were cast using 1:3 mortar with W/C ratio of 0.55 . During casting, the cylinders were mechanically vibrated using a table vibrator. After $24 \mathrm{~h}$, the specimens were removed from the mould and subjected to water curing for 28 days. After the specified curing period was over, the concrete cylinders were subjected to split tensile test. Tests were carried out on triplicate specimens and average split tensile strength values were recorded.

$$
f_{s p}=2 P / \pi d l\left(N / \mathrm{mm}^{2}\right)
$$

Where, $P$ is load at failure (N), $d$ is diameter of specimen (mm), $l$ is length of specimen $(\mathrm{mm})$

\subsubsection{Flexural Strength: (ASTM C 78-09)}

Toughness is defined as the amount of energy required to break a material (area under the load deformation curve). The test specimen of size $50 \times 10 \times 10 \mathrm{~cm}$ beam is subjected to two point loading. The load is applied to the specimen gradually until the specimen fails. The deflection is noted at the centre point of the specimen. The crack will appear when the 
specimen fails. Crack width are measured at the top, middle and bottom of the specimen using the crack width detector. The mechanism of toughness improvement in the fiber reinforced composites is mainly related to the fiber bridging effect. It is already well known that during the debonding between matrix and fiber, the fiber either eventually fractures, or is subsequently pulled out of the matrix.

\subsubsection{Impact resistance test}

Drop weight impact test, also known as repeated impact test, is conducted for evaluating the impact resistance. In this method the specimens are broken by known weight $(560 \mathrm{gm})$ dropped from various heights. The steel ball is dropped from various heights at the center of the specimen. This is the simplest method to find impact resistance. Specimen of size $300 \times 230 \times 10 \mathrm{~mm}$ was used for the investigation.

When a concrete slab is subjected to a load released from a defined height thereby constituting an impact loading, in general, there is a loss of potential energy which is absorbed and dissipated as strain energy, causing cracks due to stresses developed in the element. The width of crack thus developed is related to the intensity of the energy, the amount of energy absorbed and the properties of the concrete. The energy absorbed is dissipated in the form of crack patterns produced from the impact loading and that the crack pattern is also dependent on the properties of the concrete. A relationship for the potential energy (PE) of an impact loading due to a falling body and the strain energy dissipated in cracks.

\subsubsection{Pull out test}

Pull-out test was carried out as per IS 2770-1967-Part-1. Cold twisted deformed bars of $12 \mathrm{~mm}$ diameter and $750 \mathrm{~mm}$ long were used for steel-concrete bond strength determination. The rod was placed centrally along with helical reinforcement provided in the centre of the concrete cube of size $100 \times 100 \times$ $100 \mathrm{~mm}$ using a concrete mix of 1:1.80:3.69 with W/C ratio equal to 0.55 . Specimens with OPC and OPC replaced by rice husk ash varying from 10\%, 15\%, 20\%. The rebar is projected down for a distance of about $10 \mathrm{~mm}$ from the bottom face of the cube as cast and projected upward from the top up to $300 \mathrm{~mm}$ height in order to provide an adequate length to be gripped for application of load. During casting of concrete cubes, the moulds were mechanically vibrated. The cubes were removed from the mould after $24 \mathrm{~h}$ and then cured for 28 days with complete immersion in distilled water. After the curing period was over the steel-concrete bond strength was determined using Universal Testing Machine (Model: UTM-60) of capacity $60 t$. The bond strength was calculated from the load at which the slip was $0.25 \mathrm{~mm}$. Tests were carried out in triplicate specimens and average bond strength values were obtained.

\section{Results and discussion}

\subsection{Compressive strength}

Fig. 1, and Table 3 and 4 show the compressive strength of coconut fibers with $1 / d=66$ at various percentages ranging from $0.125 \%$ to $0.375 \%$ with $10 \%$ and $20 \%$ RHA.. From the figure it is observed that OPC+0.25\% CF+10\% RHA system is found to have higher compressive strength when compared to all the other systems. Other systems such as OPC $+0.125 \% \mathrm{CF}+10 \%$ $\mathrm{RHA}$ and $\mathrm{OPC}+10 \%$ RHA have also performed equally well compared to OPC. When compared to OPC, all the systems containing fibers and RHA has shown higher compressive strength. When compared to $10 \%$ and 20\% RHA, 10\% RHA has shown maximum compressive strength because, silica present in RHA is amorphous in nature which reacts with cement

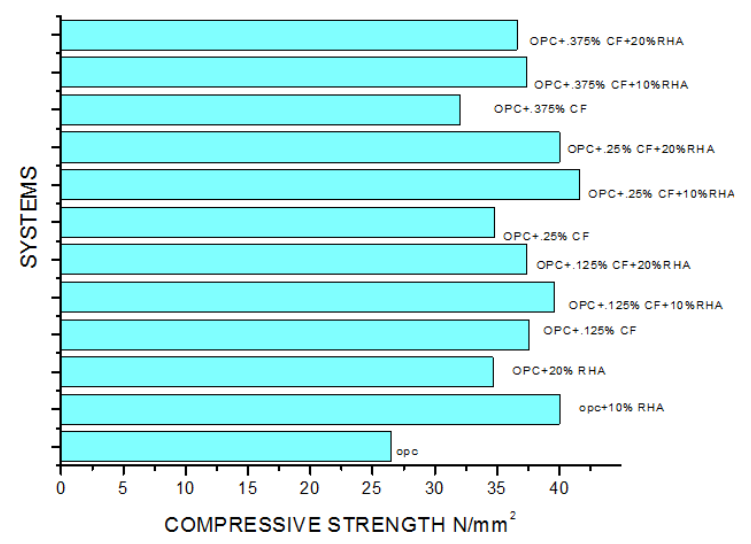

Fig. 1. Compressive Strength for Coconut fiber of length $20 \mathrm{~mm}$ 
Table 3. Compressive strength and modulus of rupture for fiber length $20 \mathrm{~mm}$

\begin{tabular}{|c|c|c|c|}
\hline S.NO & SYSTEMS & $\begin{array}{c}\text { COMPRESSIVE } \\
\text { STRENGTH } \\
\left(\mathrm{N} / \mathrm{mm}^{2}\right)\end{array}$ & $\begin{array}{c}\text { MODULUS OF } \\
\text { RUPTURE } \\
\left(\mathrm{N} / \mathrm{mm}^{2}\right)\end{array}$ \\
\hline 1 & OPC & 18.575 & 5.00 \\
\hline 2 & $\mathrm{OPC}+10 \%$ R.H.A & 40.295 & 7.04 \\
\hline 3 & $\mathrm{OPC}+20 \%$ R.H.A & 38.92 & 6.93 \\
\hline 4 & $\mathrm{OPC}+0.125 \%$ C.F & 37.435 & 6.81 \\
\hline 5 & $\begin{array}{c}\mathrm{OPC}+0.125 \% \\
\text { C.F }+10 \% \text { R.H.A }\end{array}$ & 32.08 & 6.36 \\
\hline 6 & $\begin{array}{c}\mathrm{OPC}+0.125 \% \\
\text { C.F }+20 \% \text { R.H.A }\end{array}$ & 31.355 & 6.29 \\
\hline 7 & $\mathrm{OPC}+0.125 \%$ P.F & 35.37 & 6.64 \\
\hline 8 & $\begin{array}{c}\text { OPC }+0.125 \% \\
\text { P.F }+10 \% \text { R.H.A }\end{array}$ & 36.995 & 6.78 \\
\hline 9 & $\begin{array}{c}\text { OPC }+0.125 \% \\
\text { P.F }+20 \% \text { R.H.A }\end{array}$ & 34.615 & 6.58 \\
\hline 10 & $\mathrm{OPC}+0.25 \%$ C.F & 33.2 & 6.46 \\
\hline 11 & $\begin{array}{c}\mathrm{OPC}+0.25 \% \text { C.F }+10 \% \\
\text { R.H.A }\end{array}$ & 37.4 & 6.81 \\
\hline 12 & $\begin{array}{c}\mathrm{OPC}+0.25 \% \text { C.F }+20 \% \\
\text { R.H.A }\end{array}$ & 36.3 & 6.72 \\
\hline 13 & $\mathrm{OPC}+0.25 \%$ P.F & 39.1 & 6.95 \\
\hline 14 & $\begin{array}{c}\mathrm{OPC}+0.25 \% \text { P.F }+10 \% \\
\text { R.H.A }\end{array}$ & 23.35 & 5.53 \\
\hline 15 & $\begin{array}{c}\mathrm{OPC}+0.25 \% \text { P.F }+20 \% \\
\text { R.H.A }\end{array}$ & 32.3 & 6.38 \\
\hline 16 & $\mathrm{OPC}+0.375 \%$ C.F & 36 & 6.70 \\
\hline 17 & $\begin{array}{c}\mathrm{OPC}+0.375 \% \\
\text { C.F }+10 \% \text { R.H.A }\end{array}$ & 35.4 & 6.64 \\
\hline 18 & $\begin{array}{c}\mathrm{OPC}+0.375 \% \\
\text { C.F }+20 \% \text { R.H.A }\end{array}$ & 34.1 & 6.53 \\
\hline 19 & $\mathrm{OPC}+0.375 \%$ P.F & 36 & 6.70 \\
\hline 20 & $\begin{array}{c}\mathrm{OPC}+0.375 \% \\
\text { P.F }+10 \% \text { R.H.A }\end{array}$ & 30 & 6.17 \\
\hline 21 & $\begin{array}{c}\text { OPC }+0.375 \% \\
\text { P.F }+20 \% \text { R.H.A }\end{array}$ & 31.9 & 6.34 \\
\hline
\end{tabular}

forming a durable calcium silicate hydrate which enhanced the strength of the concrete. When comparing $0.125 \%, 0.25 \%$, 0.375\% CF, 0.25\% CF addition has shown higher compressive strength values than the other two systems.

Table 3 and 4 shows the compressive strength and modulus of rupture for various systems. From the table it is found that modulus of rupture is found to be higher for the fiber added systems when compared to OPC. This indicates the flexibility of the fibers.
Table 4. Compressive strength and modulus of rupture for fiber length $40 \mathrm{~mm}$

\begin{tabular}{|c|c|c|c|}
\hline S.NO & SYSTEMS & $\begin{array}{c}\text { COMPRESSIVE } \\
\text { STRENGTH } \\
\left(\mathrm{N} / \mathrm{mm}^{2}\right)\end{array}$ & $\begin{array}{c}\text { MODULUS OF } \\
\text { RUPTURE } \\
\left(\mathrm{N} / \mathrm{mm}^{2}\right)\end{array}$ \\
\hline 1. & OPC & 18.575 & 5.01 \\
\hline 2. & OPC $+10 \%$ R.H.A & 40.295 & 7.05 \\
\hline 3. & $\mathrm{OPC}+20 \%$ R.H.A & 38.92 & 6.94 \\
\hline 4. & $\mathrm{OPC}+0.125 \%$ C.F & 36.3 & 6.73 \\
\hline 5. & $\begin{array}{c}\text { OPC }+0.125 \% \\
\text { C.F }+10 \% \text { R.H.A }\end{array}$ & 35.9 & 6.69 \\
\hline 6. & $\begin{array}{c}\mathrm{OPC}+0.125 \% \\
\text { C.F }+20 \% \text { R.H.A }\end{array}$ & 33.8 & 6.51 \\
\hline 7. & $\mathrm{OPC}+0.125 \%$ P.F & 35.1 & 6.62 \\
\hline 8. & $\begin{array}{c}\text { OPC }+0.125 \% \\
\text { P.F }+10 \% \text { R.H.A }\end{array}$ & 33.4 & 6.47 \\
\hline 9. & $\begin{array}{c}\text { OPC }+0.125 \% \\
\text { P.F }+20 \% \text { R.H.A }\end{array}$ & 32.7 & 6.41 \\
\hline 10. & $\mathrm{OPC}+0.25 \%$ C.F & 36 & 6.70 \\
\hline 11. & $\begin{array}{c}\mathrm{OPC}+0.25 \% \text { C.F }+10 \% \\
\text { R.H.A }\end{array}$ & 35.5 & 6.65 \\
\hline 12. & $\begin{array}{c}\mathrm{OPC}+0.25 \% \text { C.F }+20 \% \\
\text { R.H.A }\end{array}$ & 33.7 & 6.50 \\
\hline 13. & $\mathrm{OPC}+0.25 \%$ P.F & 31.9 & 6.34 \\
\hline 14. & $\begin{array}{c}\mathrm{OPC}+0.25 \% \text { P.F }+10 \% \\
\text { R.H.A }\end{array}$ & 29.4 & 6.12 \\
\hline 15. & $\begin{array}{c}\mathrm{OPC}+0.25 \% \text { P.F }+20 \% \\
\text { R.H.A }\end{array}$ & 18.8 & 5.03 \\
\hline 16. & $\mathrm{OPC}+0.375 \%$ C.F & 31.1 & 6.27 \\
\hline 17. & $\begin{array}{c}\mathrm{OPC}+0.375 \% \\
\text { C.F }+10 \% \text { R.H.A }\end{array}$ & 31.9 & 6.34 \\
\hline 18. & $\begin{array}{c}\text { OPC }+0.375 \% \\
\text { C.F }+20 \% \text { R.H.A }\end{array}$ & 25.5 & 5.74 \\
\hline 19. & $\mathrm{OPC}+0.375 \%$ P.F & 17 & 4.82 \\
\hline 20. & $\begin{array}{c}\text { OPC }+0.375 \% \\
\text { P.F }+10 \% \text { R.H.A }\end{array}$ & 22.4 & 5.43 \\
\hline 21. & $\begin{array}{c}\mathrm{OPC}+0.375 \% \\
\text { P.F }+20 \% \text { R.H.A }\end{array}$ & 17.6 & 4.89 \\
\hline
\end{tabular}

Fig. 2 shows the compressive strength of coconut fiber of length $40 \mathrm{~mm}$ with $\mathrm{l} / \mathrm{d}=133$. From the figure it is observed that $\mathrm{OPC}+10 \% \mathrm{RHA}$ has got maximum compressive strength of $40 \mathrm{~N} / \mathrm{mm}^{2}$. On the other hand, OPC $+0.125 \% \mathrm{CF}$ and OPC+ $0.125 \% \mathrm{CF}+10 \% \mathrm{RHA}$ has also got compressive strength of 36.5 and $36 \mathrm{~N} / \mathrm{mm}^{2}$ respectively. It is obvious that, the increase in fiber length decreases the compressive strength of the concrete. In $40 \mathrm{~mm}$ fiber length $0.125 \% \mathrm{CF}$ is found to be the optimum level. When compared to $20 \mathrm{~mm}$ and $40 \mathrm{~mm}$ length of 


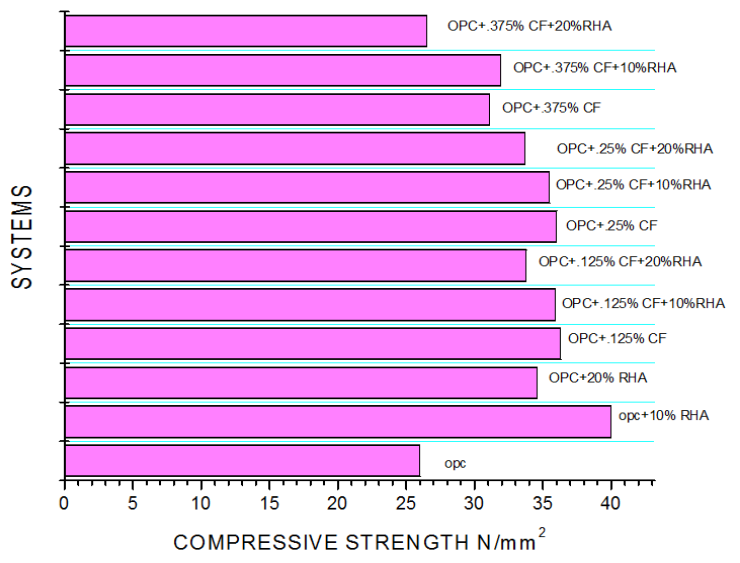

Fig. 2. Compressive Strength of Coconut fiber of length $40 \mathrm{~mm}$

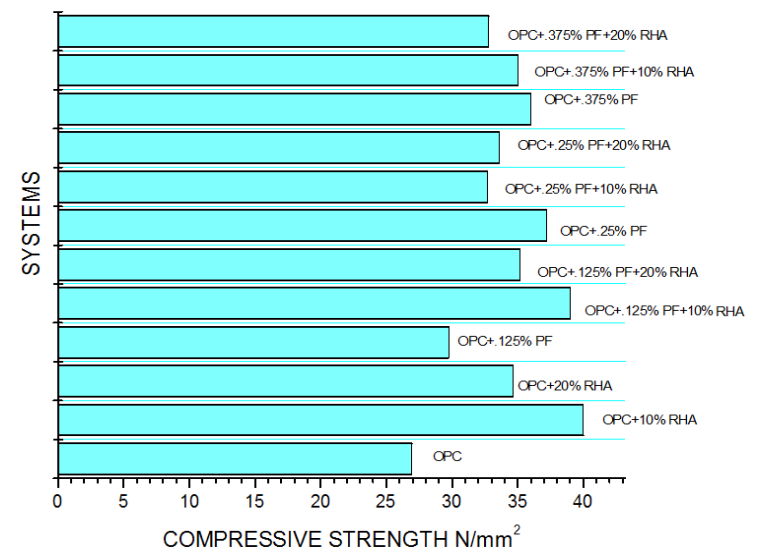

Fig. 3. Compressive Strength of Polypropylene fibers of the length $20 \mathrm{~mm}$

fiber, at 20mm length, all percentage shave greater compressive strength than $40 \mathrm{~mm}$ length fibers.

Fig. 3 shows the compressive strength of polypropylene fibers of the length $20 \mathrm{~mm}$ with $(\mathrm{l} / \mathrm{d}=1000)$ at various percentages ranging from $0.125 \%$ to $0.375 \%$ with $10 \%$ and $20 \% \mathrm{RHA}$. From the figure it is observed that, OPC $+10 \%$ RHA systems is found to have higher compressive strength when compared to all the other systems. Other systems containing OPC+0.125\% PF+10\% $\mathrm{RHA}, \mathrm{OPC}+0.25 \% \mathrm{PF}$ and $\mathrm{OPC}+0.375 \% \mathrm{PF}$ have also performed equally well compared to OPC. But when compared to OPC all the systems containing fibers and RHA have performed better. From the results it is observed that $0.125 \%$ PF is the optimum percentage of fiber addition. But when compared to PF and CF, CF has shown higher compressive

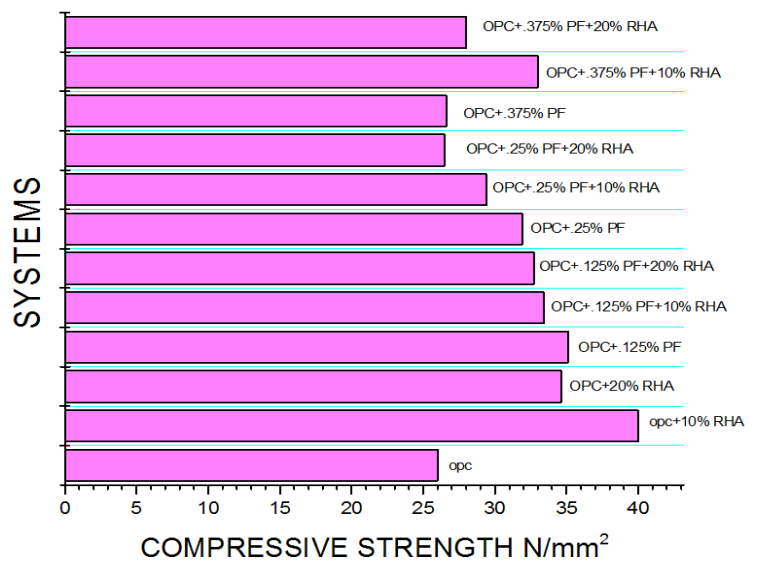

Fig. 4. Compressive Strength of Polypropylene fibers of length $40 \mathrm{~mm}$

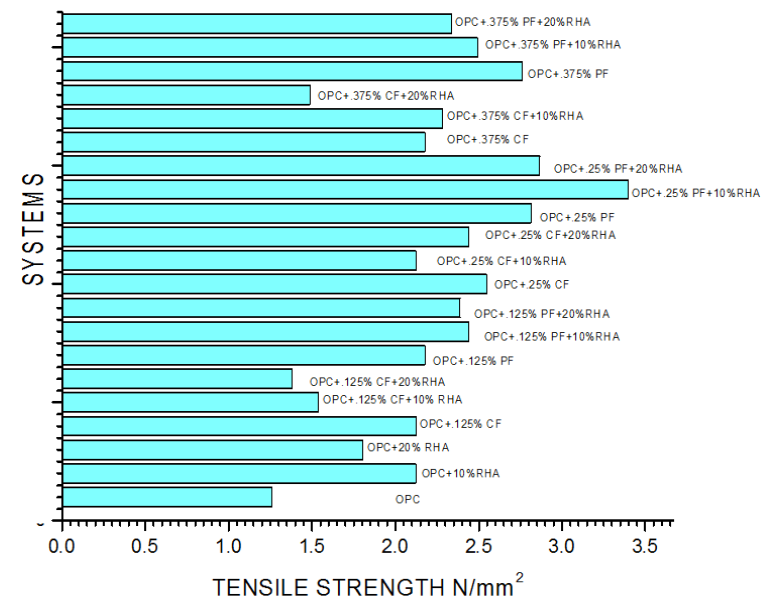

Fig. 5. Split Tensile Strength of length of $20 \mathrm{~mm}$

strength.

Fig. 4 shows the compressive strength of polypropylene fibers of length $40 \mathrm{~mm}$ with $(1 / \mathrm{d}=2000)$. From the figure it is observed that OPC+10\% RHA has got maximum compressive strength of $40 \mathrm{~N} / \mathrm{mm}^{2}$. On the other hand, OPC+0.125\% PF and OPC $+20 \%$ RHA has also got compressive strength of 35 and $34.5 \mathrm{~N} / \mathrm{mm}^{2}$ respectively. It is obvious that, the increase in fiber length decreases the compressive strength of the concrete.

In $40 \mathrm{~mm}$ fiber length $0.125 \% \mathrm{PF}$ is found to be the optimum level. In considering RHA, 10\% RHA has obtained higher compressive strength. When compared to $20 \mathrm{~mm}$ and $40 \mathrm{~mm}$ length, $20 \mathrm{~mm}$ length at all percentages have greater compressive strength of $42 \mathrm{~N} / \mathrm{mm}^{2}$. 


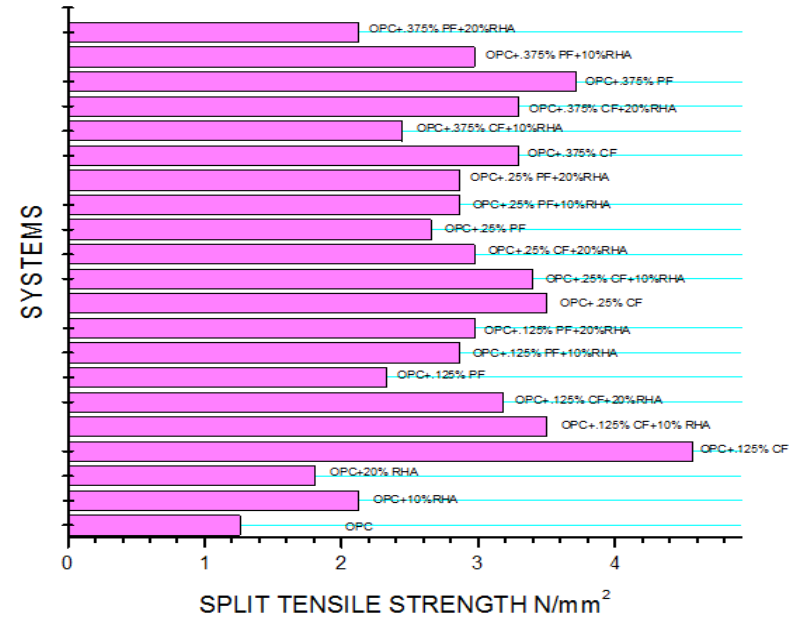

Fig. 6. Split Tensile Strength of length $40 \mathrm{~mm}$

\subsection{Split tensile strength}

Fig. 5 shows the split tensile strength of CF and PF of length of $20 \mathrm{~mm}$ with $(\mathrm{l} / \mathrm{d}=1000)$ at various percentages ranging from $0.125 \%$ to $0.375 \%$ with $10 \%$ and $20 \%$ RHA. From the figure it is observed that OPC+0.25\% PF+10\% RHA has got maximum value as $3.8 \mathrm{~N} / \mathrm{mm}^{2}$. OPC $+0.25 \% \mathrm{PF}+20 \% \mathrm{RHA}$ and $\mathrm{OPC}+$ $0.25 \%$ PF has also got better strength. OPC+20\% RHA got minimum value of $1.8 \mathrm{~N} / \mathrm{mm}^{2}$. The optimum value of polypropylene fibers is $0.25 \%$. When compared to coconut fiber OPC+0.25\% CF has the value of $2.5 \mathrm{~N} / \mathrm{mm}^{2}$. When compared to coconut fiber and polypropylene fibers, polypropylene fibers perform higher strength.

Fig. 6 shows the split tensile strength of length $40 \mathrm{~mm}$ with $(\mathrm{l} / \mathrm{d}=2000)$ at various percentages ranging from $0.125 \%$ to $0.375 \%$ with $10 \%$ and $20 \%$ RHA. From the graph it is observed that the OPC $+0.125 \% \mathrm{CF}$ have obtained higher strength of $4.6 \mathrm{~N} / \mathrm{mm}^{2}$. On the other side OPC+0.125\% CF+10\% RHA and OPC $+0.25 \%$ CF has also obtained higher value. When compared to opc+20\% RHA all the other systems got higher strength. In considering polypropylene fibers OPC+0.375\% PF has got maximum strength while considering other system of polypropylene fibers. On comprising that coconut fiber performs well.

\subsection{Flexural strength}

Fig. 7 shows the flexural strength of $20 \mathrm{~mm} \mathrm{CF}$ and PF length with $(1 / d=66$ and $I / d=1000)$ at the volume fraction of $0.125 \%$

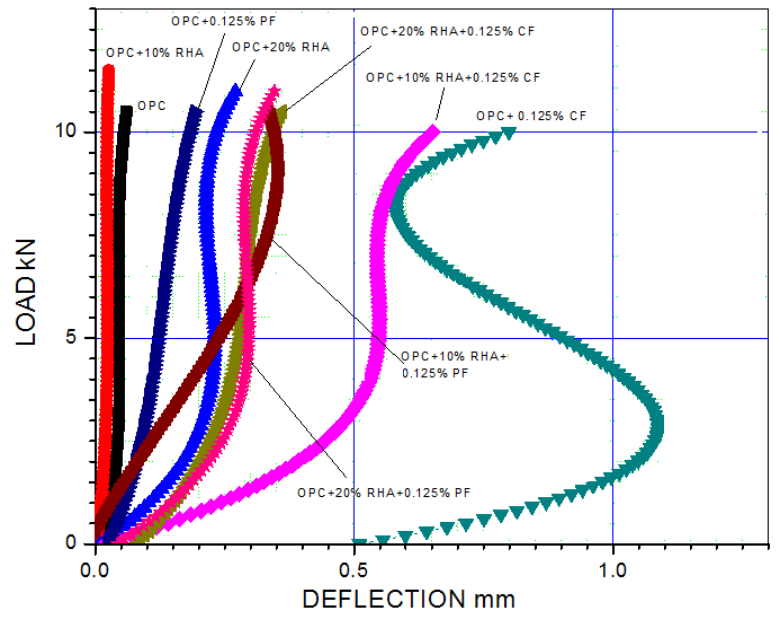

Fig. 7. Flexural Strength of length $20 \mathrm{~mm}\left(V_{f}=0.125 \%\right)$

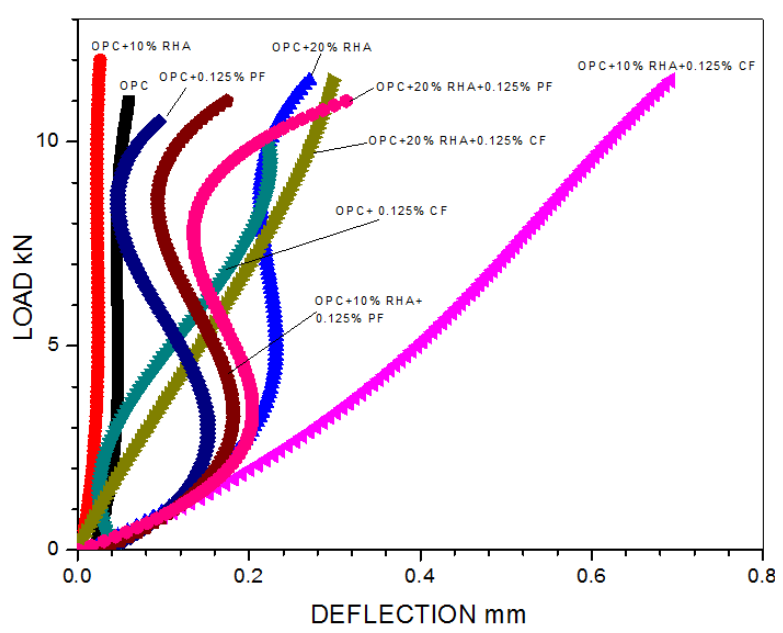

Fig. 8. Flexural Strength of length $40 \mathrm{~mm}\left(V_{f}=0.125 \%\right)$

with $10 \%$ and $20 \%$ RHA.

From the observation, OPC $+0.125 \% \mathrm{CF}$ has obtained maximum deflection of $1.2 \mathrm{~mm}$. OPC $+10 \% \mathrm{RHA}+0.125 \% \mathrm{CF}$ has got a deflection of $0.65 \mathrm{~mm}$. OPC $+10 \%$ RHA has got minimum deflection of $0.05 \mathrm{~mm}$ due to the absence of fiber content. From the results it is found that the maximum deflection is due to the addition of fiber. While considering the polypropylene fibers OPC+20\% RHA+0.125\% PF has got maximum deflection. Coconut fiber performs well in the volume fraction of $0.125 \%$.

Fig. 8 shows the flexural strength of $40 \mathrm{~mm}$ CF and PF with $(\mathrm{l} / \mathrm{d}=133$ and $\mathrm{I} / \mathrm{d}=2000)$ at the volume fraction of $0.125 \%$ with 10\% and 20\% RHA. From the observation OPC+0.125\% CF+10\% 
RHA has obtained maximum deflection of $0.7 \mathrm{~mm}$. On the other hand, OPC+20\% RHA+0.125\% PF and OPC+20\% RHA+ $0.125 \%$ CF has also perform well. While compared to coconut fiber and polypropylene fibers, coconut fiber performs well in the volume fraction of $0.125 \%$. On other side compared to $\mathrm{I} / \mathrm{d}$ ratio of 133 and 2000 fiber, the toughness is higher for $20 \mathrm{~mm}$ fiber length. Thus considering the flexural strength $20 \mathrm{~mm}$ length fiber has got higher flexural strength.

Fig. 9 shows the flexural strength of $20 \mathrm{~mm}$ fiber with $(1 / \mathrm{d}$ $=66$ and $\mathrm{I} / \mathrm{d}=1000$ ) at the volume fraction of $0.25 \%$ with $10 \%$ and 20\% RHA. From the graph, OPC+0.25\% CF+10\% RHA has obtained maximum deflection of $1.04 \mathrm{~mm}$. Other words, OPC+ 20\% RHA+0.25\% PF, has also got good deflection behavior. The minimum deflection obtained in the system of OPC $+10 \%$ $\mathrm{RHA}$ because, the fiber gives additional strength to concrete.

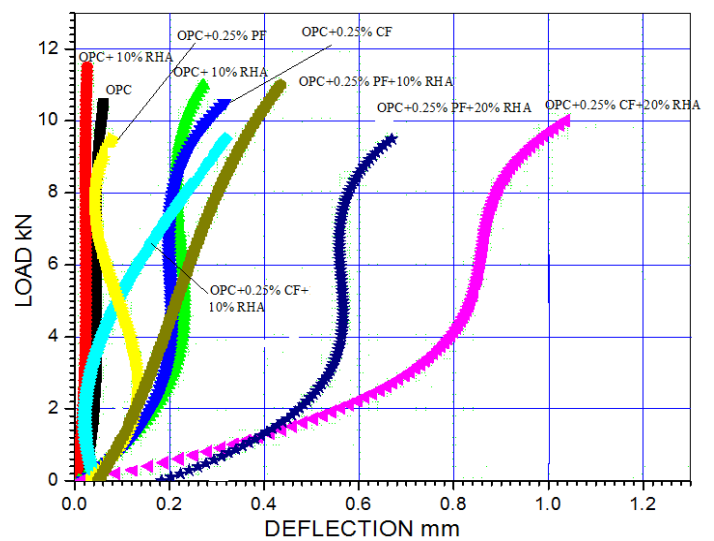

Fig. 9. Flexural Strength of length $20 \mathrm{~mm}\left(V_{f}=0.25 \%\right)$

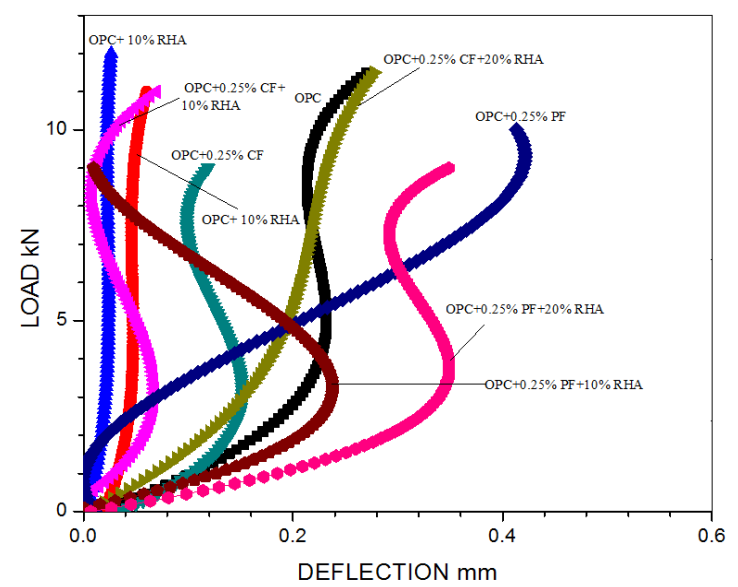

Fig. 10. Flexural Strength of length $40 \mathrm{~mm}\left(V_{f}=0.25 \%\right)$
Considering RHA, 10\% RHA got high deflection in 0.125\% and $0.25 \%$ of fiber. When comparing to coconut fiber and polypropylene fibers, coconut fibers performs well in the volume fraction of $0.25 \%$. In volume fraction consideration $0.125 \%$ has obtained maximum deflection.

Fig. 10 shows the flexural strength of $40 \mathrm{~mm}$ fiber with $(\mathrm{I} / \mathrm{d}$ $=133$ and $\mathrm{l} / \mathrm{d}=2000$ ) at the volume fraction of $0.25 \%$ with 10\% and 20\% RHA. From the observation OPC+0.125\% PF has obtained maximum deflection of $0.45 \mathrm{~mm}$. In other words, OPC+0.25\% PF+20\% RHA, OPC+0.25\% CF+20\% RHA and OPC has also performs well. The minimum deflection of $0.01 \mathrm{~mm}$ has obtained for the system OPC+10\% RHA+0.25\% PF. While compared to coconut fiber and polypropylene fibers, polypropylene fibers perform well in the volume fraction of $0.25 \%$. The toughness is higher for $20 \mathrm{~mm}$ fiber length. Thus considering the strength factor, $1 / d=66$ performs high.

Fig. 11 shows the flexural strength of $20 \mathrm{~mm}$ fiber with $(1 / \mathrm{d}$ $=66$ and $\mathrm{l} / \mathrm{d}=1000$ ) at the volume fraction of $0.375 \%$ with 10\% and 20\% RHA. From the graph, OPC+0.375\% CF+10\% RHA has obtained maximum deflection of $1.58 \mathrm{~mm}$. In other words, OPC+20\% RHA+0.375\% PF, has also got well deflection. The minimum deflection obtained in the system of OPC $+10 \% \mathrm{RHA}$ because of the absence of fiber content. In consideration of $\mathrm{RHA}, 10 \%$ RHA got high deflection in $0.125 \%$ and $0.25 \%$ of fiber. While compared to coconut fiber and polypropylene fibers, polypropylene fibers performs well in the volume fraction of $0.375 \%$. In volume fraction consideration $0.375 \%$ has obtained

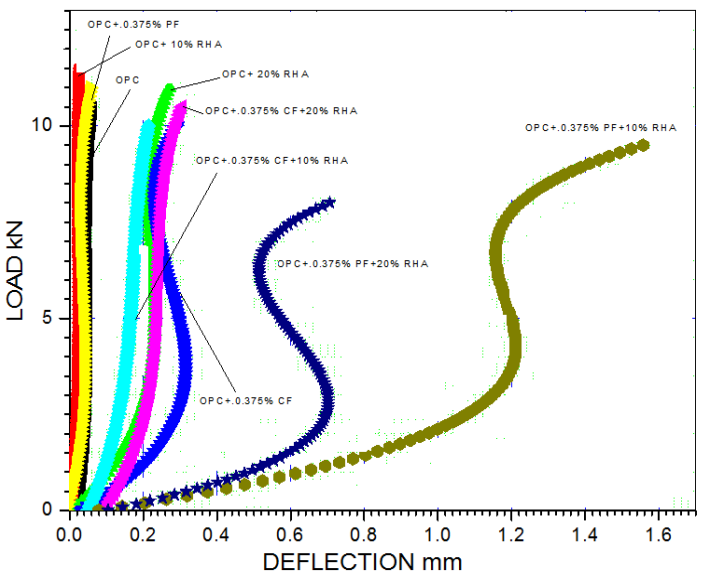

Fig. 11. Flexural Strength of length $20 \mathrm{~mm}\left(V_{f}=0.375 \%\right)$ 
maximum deflection. The optimum value for polypropylene fibers is $0.375 \%$. As the result comprising on polypropylene fibers, the volume fraction increases the deflection increases.

Fig. 12 shows the flexural strength of $40 \mathrm{~mm}$ CF and PF with $(\mathrm{I} / \mathrm{d}=133$ and $\mathrm{I} / \mathrm{d}=2000)$ at the volume fraction of $0.375 \%$ with $10 \%$ and $20 \%$ RHA. From the observation OPC+0.375\% $\mathrm{PF}+10 \%$ RHA has obtained maximum deflection of $0.39 \mathrm{~mm}$. The minimum deflection of 0.01 has obtained for the system OPC $+0.375 \%$ CF. While compared to coconut fiber and polypropylene fibers, polypropylene fibers performs well in the volume fraction of $0.375 \%$. In consideration of RHA, $10 \%$ RHA got high deflection in $0.125 \%$ and $0.25 \%$ and $0.375 \%$ of fiber. As the result comprising on polypropylene fibers, the volume fraction increases the deflection increases and for coconut

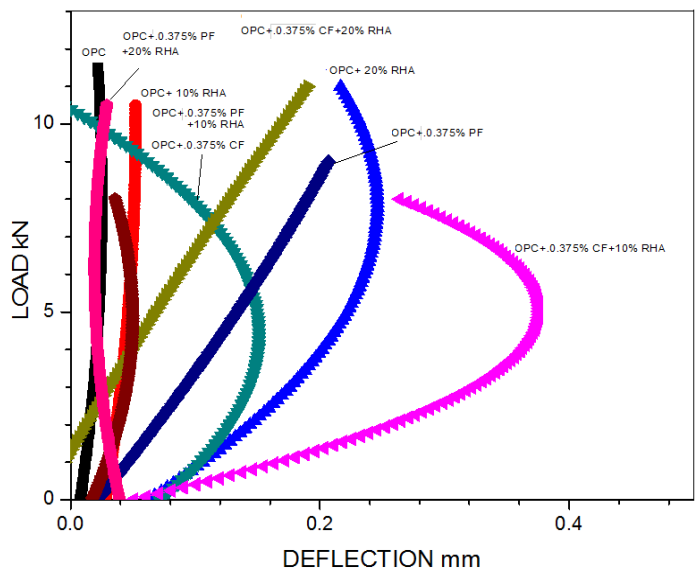

Fig. 12. Flexural Strength of length $40 \mathrm{~mm}\left(V_{f}=0.375 \%\right)$

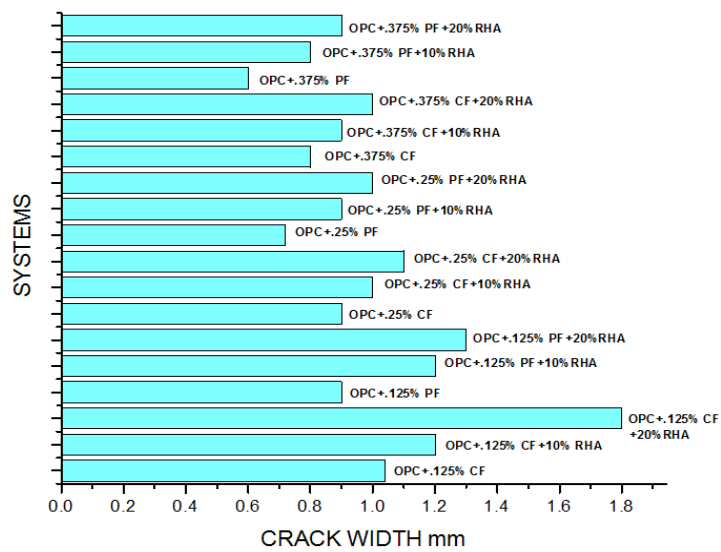

Fig. 13. Crack Width of $20 \mathrm{~mm} \mathrm{CF}$ and PF (tensile zone) fiber the volume fraction increases the deflection decreases. In this the optimum value of volume fraction for coconut fiber is $0.125 \%$. The optimum value of volume fraction for polypropylene fibers is $0.375 \%$. By increasing the length of the fiber from $20 \mathrm{~mm}$ to $40 \mathrm{~mm}$, 5times decrease in deflection was observed.

Fig. 13 shows the crack width of $20 \mathrm{~mm}$ CF and PF with $(1 / \mathrm{d}$ $=66$ and $\mathrm{I} / \mathrm{d}=1000$ ) at the volume fraction of $0.125 \%, 0.25 \%$ and $0.375 \%$ with $10 \%$ and $20 \%$ RHA. From the observation OPC $+0.375 \%$ CF has obtained Minimum crack of $0.6 \mathrm{~mm}$. The maximum crack width of $1.8 \mathrm{~mm}$ has obtained for the system OPC $+0.125 \% \mathrm{CF}+20 \%$ RHA. While compared to coconut fiber and polypropylene fibers, polypropylene fibers performs well in the volume fraction of $0.375 \%$. In consideration of RHA, $10 \%$ $\mathrm{RHA}$ got minimum crack width in $0.125 \%$ and $0.25 \%$ and $0.375 \%$ of fiber. As the result comprising on polypropylene fibers and coconut fiber, the volume fraction increases the crack width decreases. fiber addition prevents the brittle failure of concrete and hence reduces the plastic shrinkage cracking.

Fig. 14 and 15 depict the crack pattern of CF and PF fiber added flexural strength tested concrete beams. From the figures it is obvious that addition of fibers reduced the ductile behavior of concrete.

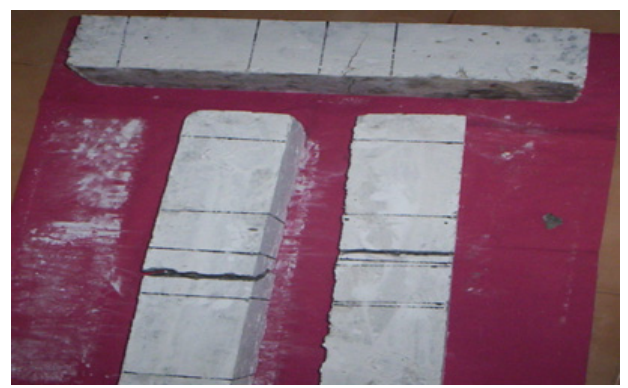

Fig. 14. Difference between Crack Width

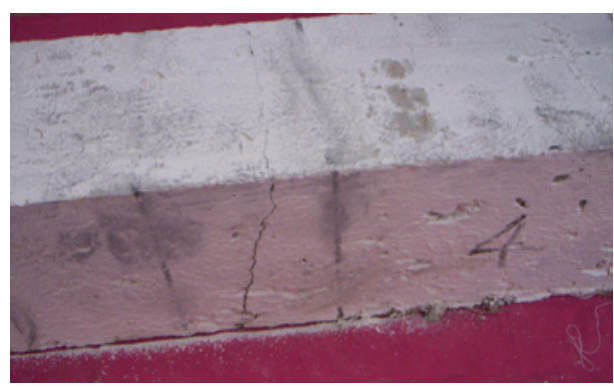

Fig. 15. Crack pattern for coconut fiber added concrete 
Fig. 16 shows the crack width of $40 \mathrm{~mm} \mathrm{CF}$ and PF with (I/d $=133$ and $\mathrm{l} / \mathrm{d}=2000$ ) at the volume fraction of $0.125 \%, 0.25 \%$ and $0.375 \%$ with $10 \%$ and 20\% RHA. From the observation OPC $+0.375 \% \mathrm{CF}+20 \%$ RHA has obtained Minimum crack of $0.05 \mathrm{~mm}$. The maximum crack width of $1.6 \mathrm{~mm}$ has obtained for the system OPC+0.125\%CF+20\% RHA. While compared to coconut fiber and polypropylene fibers, coconut fibers performs well in the volume fraction of $0.375 \%$. In consideration of RHA, $10 \%$ RHA got minimum crack width in $0.125 \%$ and $0.25 \%$ and $0.375 \%$ of fiber. As the result comprising on polypropylene fibers and coconut fiber, the volume fraction increases the crack width decreases. As, the result concrete is weak in tension and strong in compression. Fiber in the concrete allows the concrete to perform as ductile materials.

\subsection{Impact test}

Fig. 17 shows the Impact energy at 20mm CF and PF fiber

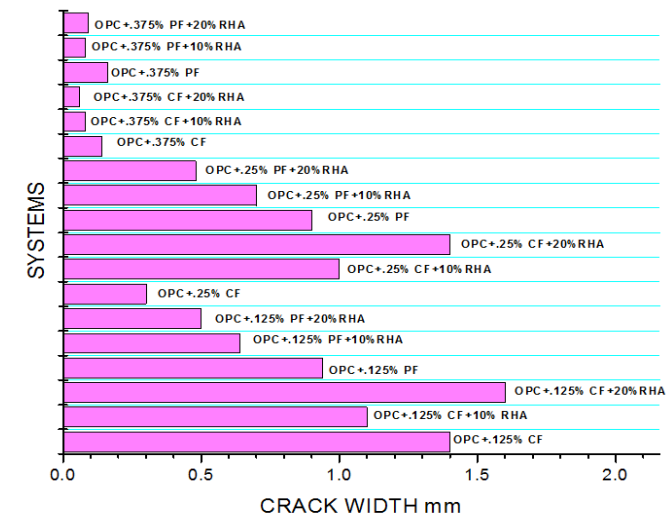

Fig. 16. Crack Width of $40 \mathrm{~mm}$ CF and PF (tensile zone)

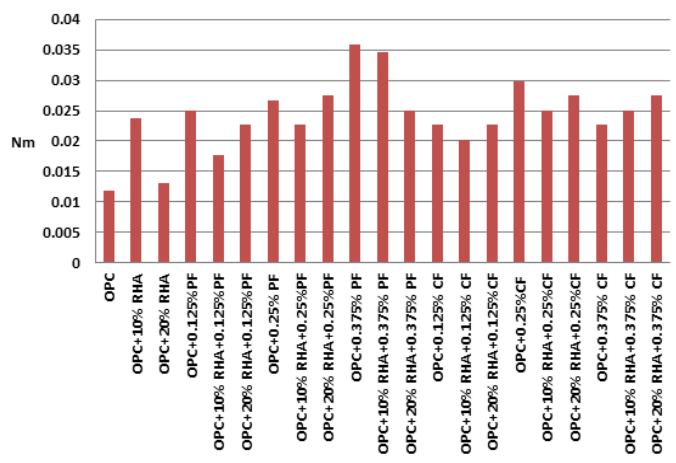

Fig. 17. Impact Energy of length $20 \mathrm{~mm}$ with $(\mathrm{l} / \mathrm{d}=66$ and $\mathrm{l} / \mathrm{d}=1000)$ various percentages ranging from $0.125 \%$ to $0.375 \%$ with $10 \%$ and $20 \%$ RHA. From the figure it is observed that OPC $+0.375 \% \mathrm{CF}+20 \%$ RHA system is found to have higher impact energy of $0.0356 \mathrm{Nm}$ when compared to all the other systems. Other systems such as OPC+0.25\% $\mathrm{CF}+20 \% \mathrm{RHA}$ and $\mathrm{OPC}+0.375 \% \mathrm{CF}+20 \%$ RHA have also performed well compared OPC. In considering polypropylene fibers, the maximum is energy obtained for the system OPC+ $0.375 \%$ PF. But when compared to OPC all the systems containing fibers and RHA have performed better. The optimum value of volume fraction coconut fiber is $0.25 \%$ and for polypropylene fibers is $0.375 \%$. When comparing $0.125 \%$, $0.25 \%, 0.375 \%$ of volume fraction, the volume fraction of $0.375 \%$ performs well.

\subsection{Bond strength}

Table 5 depict the bond strength of various systems containing CF and PF fiber along with RHA at 10 and 20\%

Table 5. Bond strength with and without CF and PF at various percentages

\begin{tabular}{|c|c|c|}
\hline Sl.No. & Systems & Bond Strength $\mathrm{N} / \mathrm{mm}^{2}$ \\
\hline 1 & - & 6.91 \\
\hline 2 & $\mathrm{OPC}+10 \%$ RHA & 9.42 \\
\hline 3 & $\mathrm{OPC}+200 \%$ RHA & 9.28 \\
\hline 4 & $\mathrm{OPC}+0.125 \% \mathrm{CF}$ & 11.41 \\
\hline 5 & $\mathrm{OPC}+0.125 \% \mathrm{CF}+10 \% \mathrm{RHA}$ & 11.80 \\
\hline 6 & $\mathrm{OPC}+0.125 \% \mathrm{CF}+20 \% \mathrm{RHA}$ & 9.02 \\
\hline 7 & $\mathrm{OPC}+0.25 \% \mathrm{CF}$ & 9.81 \\
\hline 8 & $\mathrm{OPC}+0.25 \% \mathrm{CF}+10 \% \mathrm{RHA}$ & 6.76 \\
\hline 9 & $\mathrm{OPC}+0.25 \% \mathrm{CF}+20 \%$ RHA & 6.37 \\
\hline 10 & $\mathrm{OPC}+0.375 \% \mathrm{CF}$ & 7.43 \\
\hline 11 & $\mathrm{OPC}+0.375 \% \mathrm{CF}+10 \% \mathrm{RHA}$ & 10.48 \\
\hline 12 & $\mathrm{OPC}+0.375 \% \mathrm{CF}+20 \% \mathrm{RHA}$ & 7.80 \\
\hline 13 & $\mathrm{OPC}+0.125 \% \mathrm{PF}$ & 11.54 \\
\hline 14 & $\mathrm{OPC}+0.125 \% \mathrm{PF}+10 \%$ RHA & 9.02 \\
\hline 15 & $\mathrm{OPC}+0.125 \% \mathrm{PF}+20 \% \mathrm{RHA}$ & 6.633 \\
\hline 16 & $\mathrm{OPC}+0.25 \% \mathrm{PF}$ & 8.22 \\
\hline 17 & $\mathrm{OPC}+0.25 \% \mathrm{PF}+10 \% \mathrm{RHA}$ & 8.49 \\
\hline 18 & $\mathrm{OPC}+0.25 \% \mathrm{PF}+20 \% \mathrm{RHA}$ & 6.76 \\
\hline 19 & $\mathrm{OPC}+0.375 \% \mathrm{PF}$ & 7.29 \\
\hline 20 & $\mathrm{OPC}+0.375 \% \mathrm{PF}+10 \% \mathrm{RHA}$ & 8.22 \\
\hline 21 & $\mathrm{OPC}+0.375 \% \mathrm{PF}+20 \% \mathrm{RHA}$ & 8.62 \\
\hline
\end{tabular}


replacement levels. From the results it is observed that the bond strength was enhanced for all the fiber additions and also RHA replacement has not affected the bond strength of the concrete. It is interesting to note that systems containing OPC+ 10\% RHA+ 0.125\%CF, OPC+ $0.125 \%$ PF and OPC $+0.125 \%$ CF has got maximum bond strength of $11.803,11.538$ and $11.405 \mathrm{~N} / \mathrm{mm}^{2}$ respectively. When compared to $10 \%$ and $20 \%$ replacement of $\mathrm{RHA}, 20 \% \mathrm{RHA}$ along with fibers has lesser bond strength values.

\section{Conclusions}

Following conclusions can be drawn from the above investigation:

1. Compressive strength results revealed that,

- It is observed that OPC $+0.25 \% \mathrm{CF}+10 \% \mathrm{RHA}$ system is found to have higher compressive strength when compared to all the other systems.

- When comparing 20 and $40 \mathrm{~mm}$ length, $20 \mathrm{~mm}$ length has shown higher compressive strength.

- When comparing CF and PF, CF has got maximum compressive strength.

2. Spilt tensile strength results revealed that,

- It is observed that OPC+0.25\% PF+10\% RHA has got maximum value of $3.8 \mathrm{~N} / \mathrm{mm}^{2}$.

- It is observed that the OPC+0.125\% CF have obtained higher strength of $4.6 \mathrm{~N} / \mathrm{mm}^{2}$.

- When comparing 20 and 40mm length, 40mm length has shown higher split tensile strength.

3. Flexural strength results revealed that,

- It is observed that OPC+ 0.375\% PF+ 10\% RHA has obtained maximum deflection of $1.58 \mathrm{~mm}$.

- While compared to coconut fiber and polypropylene fibers, coconut fiber performs well in the volume fraction of $0.125 \%$.

- When comparing $20 \mathrm{~mm}$ and $40 \mathrm{~mm}$ length, $20 \mathrm{~mm}$ is having higher modulus of rupture.
4. Crack width measurements revealed that,

- It has been observed that OPC+ 0.375\% CF+ 20\% RHA has obtained minimum crack width of $0.05 \mathrm{~mm}$

- When comparing 20 and $40 \mathrm{~mm}$ length, $40 \mathrm{~mm}$ length has shown minimum crack width.

- When comparing CF and PF, CF has got minimum crack width.

5. Impact strength results revealed that,

- OPC+0.375\% PF system is found to have higher impact energy of $0.0356 \mathrm{Nm}$

- It is observed that OPC+ $0.25 \% \mathrm{CF}$ system is found to have higher impact energy of $0.03 \mathrm{Nm}$

- When comparing CF and PF, PF has got maximum impact strength.

6. Bond strength measurements revealed that,

- It is interesting to note that systems containing OPC+ 10\% $\mathrm{RHA}+0.125 \% \mathrm{CF}, \mathrm{OPC}+0.125 \% \mathrm{PF}$ and OPC+ $0.125 \% \mathrm{CF}$ has got maximum bond strength of 11.80, 11.54 and $11.41 \mathrm{~N} / \mathrm{mm}^{2}$ respectively.

- When compared to $10 \%$ and $20 \%$ replacement of RHA, $20 \%$ RHA along with fibers has lesser bond strength values.

\section{Acknowledgement}

This research was supported by Basic Science Research Program through the National Research Foundation of Korea (NRF) funded by the Ministry of Education (NRF-2013R1A 1A2060114).

\section{References}

Atis, C.D., Karahan, O., Ari, K., Celik Sola, Ö., and Bilim, C. (2009), Relation between Strength Properties (Flexural and Compressive) and Abrasion Resistance of fiber (Steel and Polypropylene)-Reinforced Fly Ash Concrete, Journal of Materials in Civil Engineering, 21(8), 402-408.

Banthia, N. and Gupta, R. (2006), Influence of polypropylene 
fiber geometry on plastic shrinkage cracking in concrete, Cement and Concrete Research, 36(7), 1263-1267.

Hwang, S., Song, P.S., and Sheu, B.C. (2003), Impact resistance of polypropylene fiber reinforced concrete, Journal of C.C.I.T, 32(1).

Hwang, S., Song, P.S., and Sheu, B.C. (2003), Impact resistance of polypropylene fiber reinforced concrete, Journal of C.C.I.T, 32(1).

Kannan, S.U., Selvamony, C., Ravikumar, M.S., and Basil Gnanappa, S. (2010), Investigations and study on the effect of AR glass polymer fibers in self-compacting self-curing concrete, ARPN Journal of Engineering and Applied Sciences, 5(2), 41-45.

Karahan, O. and Atis, C.D. (2011), The durability properties of polypropylene fiber reinforced fly ash concrete, Materials and Design, 32, 1044-1049.

Kayali, O. (2004), Effect of high volume fly ash on mechanical properties of fiber reinforced concrete, Materials and Structures, 37, 318-327.

Li, B.X. Chen, M.X., Cheng, F., and Liu, L.P. (2004), The mechanical properties of polypropylene fiber reinforced concrete, Journal of Wuhan University of Technology -Materials Science Edition, 19(3), 68-71.

Mazaheripour, H., Ghanbarpour, S., Mirmoradi, S.H., and Hosseinpour, I. (2011), The effect of polypropylene fibers on the properties of fresh and hardened lightweight selfcompacting concrete, Construction and Building Materials,

25, 351-358.

Mtasher, R.A., Abbas, A.M., and Ne'ma, N.H. (2011), Strength prediction of polypropylene fiber reinforced concrete, Eng.\&Tech. Journal, 29(2), 305-311.

Nanni, A., Ludwig, D.A., and Mcgillis, M.T. (1993), Plastic shrinkage cracking of restrained fiber-reinforced concrete, Transport Res Rec(1382), 69-72.

Nataraja, M.C., Nagaraj, T.S., and Basavaraja, S.B. (2005), Reproportioning of steel fiber reinforced concrete mixes and their impact resistance, Cement and Concrete Research, 35, 2350-2359.

Nili, M. and Afroughsabet, V. (2010), The effects of silica fume and polypropylene fibers on the impact resistance and mechanical properties of concrete, Construction and Building Materials, 24, 927-933.

Ozger, O.B., Girardi, F., Giannuzzi, G.M., Salomoni, V.A., Majorana, C.E., Fambri, L., Baldassino, N., and Di Maggio, R. (2013), Effect of nylon fibers on mechanical and thermal properties of hardened concrete for energy storage systems, Materials \& Design, 51, 989-997.

Ramadoss, P. and Nagamani, K. (2008), Tensile strength and durability characteristics of high performance fiber reinforced concrete, The Arabian Journal for Science and Engineering, 33(2B), 307-319.

Ramujee, K. (2013), Strength properties of polypropylene fiber reinforced concrete, International Journal of Innovative Research in Science, Engineering and Technology, 2(8).

Sekar, T. (2004), fiber reinforced concrete from industrial waste fibers- a feasibility study, IE(I) Journal, 84, 87-290.

Shukla, M. (2011), Behavior of reinforced concrete beams with steel fibers under flexural Loading, International Journal of Earth sciences and Engineering, 4(6), 843-846.

Singh, S.P., Singh, A.P., and Bajaj, V. (2010), Strength and Flexural Toughness of Concrete Reinforced with Steel Polypropylene Hybrid Fibers, Asian journal of civil engineering(building and housing), 11(4), 495-507.

Sivakumar, A. and Santhanam, M. (2007), A quantitative study on the plastic shrinkage cracking in high strength hybrid fiber reinforced concrete, Cement and Concrete Composites, 29(7), 575-581.

Song, P.S., Hwang, S., and Sheu, B.C. (2005), Strength properties of nylon and polypropylene fiber reinforced concretes, Cement and Concrete Research, 35, 1546-1550. Sounthararajan, V.M. and Sivakumar, A. (2013), Performance Evaluati on of Metallic Fibers on the Low and high Volume Class F Fly ash based Cement Concrete, International Journal of Engineering and Technology, 5(2), 606-619.

Sounthararajan, V.M., Jain, A., Singh, A. K., Thirumurugan, S., and Sivakumar, A. (2013), Evaluation of composite polypropylene fiber reinforced concrete, International Journal of Engineering and Technology, 5(2), 1817-1828.

Vinu, R., Patel, and Pandya, I.I. (2010), Evaluation of Shear Strain Distribution In Polypropylene Fiber Reinforced 
Cement Concrete Moderate Deep Beams, International Journal of Civil And Structural Engineering, ISSN 0976 4399, 1(3).

Zhang, P. and Li, Q. (2013), Fracture Properties of Polypropylene
Fiber Reinforced Concrete Containing Fly Ash and Silica Fume, Research Journal of Applied Sciences, Engineering and Technology, 5(2), 665-670. 